\title{
Fuelling dissent
}

\author{
As the yellow vests protests in France continue despite rollback of planned fuel taxes, energy science and policy \\ will have to rethink how they look at social unrest.
}

$\mathrm{M}$ any countries with ambitious nationally determined contributions for reducing greenhouse gas emissions identify fuel taxation both as a tool for curbing fossil fuel usage and for financing renewable energy initiatives. While a number of studies have identified disproportionate distributional impacts of these taxes on various segments of society ${ }^{1}$, there has been continuing support for such measures in Western European countries with high levels of environmental awareness and ambitious national climate targets. Even if recognized as a difficult policy to implement, the taxes until recently weren't considered potential flash points for instigation of anti-government populist movements. Yet that is exactly what appears to have happened over the past few months in France.

The French yellow vests protests started in response to a proposed gasoline tax increase of about $€ 0.029$ per litre that was going to go into effect in 2019. This tax hike had followed previous tax increases. The protestors wore yellow vests because French drivers are mandated to carry them in their vehicles, making them both readily available to most and a symbol of official mandates. The resistance was triggered by an online petition calling for a repeal of the proposed tax, among other things. The online dissent flooded over into street protests by mid-November 2018 . The government was initially dismissive but as the protests intensified it backed down, suspending the planned tax hike and offering other concessions.

Carbon taxes have long been seen as a difficult climate policy to implement. Public acceptance is easier to earn with gradual implementation, higher if the taxation is progressive and revenues progressively distributed, and rises once the taxes are in place $^{2,3}$. Governments thus already approach fuel taxes with caution, generally aiming for more conservative rates compared with scientific recommendations for meeting climate targets. The yellow vests movement and its aftermath now represents one of the first examples of rapid reversal of planned government climate action at the national level in response to a direct and targeted grass roots movement and adds to the complexity of fuel tax implementation.

It would also be imprudent to dismiss the yellow vests protests and their outcome as a one-off event. Just by virtue of the reversal of government policy it achieved, the movement could encourage opponents of climate action elsewhere to instigate protests that could end up delegitimizing socially costly energy and environment policies, even if there is majority support for them. In any case, the yellow vests movement will likely make governments more wary of pursuing such taxation and further complicate wider adoption of this policy measure.

Of course, it is inaccurate to see the yellow vests protests as a response to fuel taxes alone. Such taxation has long been known to have an inordinate negative affect on the poor. One recent study of the distributional impacts of carbon taxation in France found that unless the revenues from the taxes are recycled back to low-income households through cash transfers, the taxes increase fuel poverty ${ }^{1}$. Energy justice scholars have been emphasizing the need to distribute the costs and benefits of climate mitigation and energy transition equitably. It is clear that energy policy continues to lag behind in this domain and climate taxation appears to exacerbate existing economic inequalities. The yellow vests movement is cognizant of the broader socioeconomic issues at play. The demands of the protestors are not only limited to a moratorium on specific fuel taxes but also focus on a broader list of issues calling for more equal distribution of income and wealth and more just taxation to meet climate targets. The fuel taxes in this case became the kindling that lit a bonfire that had been building for a while.

Energy policy should be mitigating this distributional disparity. In attempting to inform policy, scenario modelling could do more to examine the effects of rising disparities, including the emergence of social unrest. However, predicting the timing or probability of unanticipated social unrest and any resulting policy reversals in scenario-modelling exercises is a very difficult task.

Currently, integrated modelling exercises that look at socioeconomic pathways assume specific levels of continuous policy support. In the case of the yellow vests movement though, we have a country that appeared to be heading in one direction in terms of energy and climate policies suddenly being made to alter course through an event whose timing could not have been predicted even if it could be anticipated. The Fukushima disaster similarly led to extensive policy reversals in Germany and other European nations in a way that could not have been predicted $^{4}$. Scenario modelling could have envisioned pathways with or without nuclear, but the change in plans itself is something that could not have been built into the model, at least not with an accurate estimate of the timing.

If confounding factors such as higherintensity weather events, resource- or climate-based social unrest, and cascading failures become more common, we might need to look at scenarios of the future with potentially extreme discontinuities and uncertainties. While uncertainty quantification has long been a key element of scenario-modelling science - with ensembles and shared pathways favoured in lieu of specific single scenarios - it remains to be seen how, if at all, discontinuities in policy processes can be visualized. At least, the potential tipping points for any given scenario pathway - that may drastically alter the eventual outcomes beyond the power of the model to predict with any degree of accuracy - could be identified ${ }^{5}$.

Nonetheless we should realize that if underlying asymmetries in distribution of subsidies for changing energy systems and taxation to facilitate the energy transition are not addressed, they can become an added source of policy uncertainty at a time when more certainty and more action are required.

Published online: 13 February 2019 https://doi.org/10.1038/s41560-019-0344-z

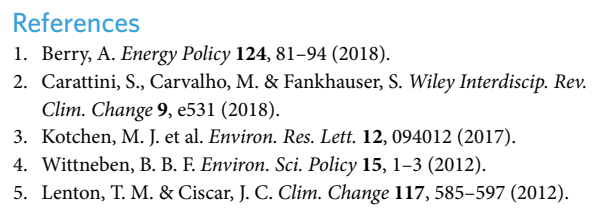

